\title{
Socioeconomic gradient in health: mind the gap in 'invisible' disparities
}

\author{
Marialaura Bonaccio ${ }^{1}$, Augusto Di Castelnuovo ${ }^{2}$, Giovanni de Gaetano ${ }^{1}$, Licia Iacoviello ${ }^{1,3}$ \\ ${ }^{1}$ Department of Epidemiology and Prevention, IRCCS NEUROMED, Pozzilli (IS), Italy; ${ }^{2}$ Mediterranea Cardiocentro, Napoli, Italy; ${ }^{3}$ Department \\ of Medicine and Surgery, Research Center in Epidemiology and Preventive Medicine (EPIMED), University of Insubria, Varese, Italy \\ Correspondence to: Dr. Marialaura Bonaccio. Department of Epidemiology and Prevention, IRCCS NEUROMED, via dell'Elettronica, 86077 Pozzilli \\ (IS), Italy. Email: marialaura.bonaccio@neuromed.it. \\ Comment on: Laine JE, Baltar VT, Stringini S, et al. Reducing socio-economic inequalities in all-cause mortality: a counterfactual mediation approach. \\ Int J Epidemiol 2020;49:497-510.
}

Submitted Mar 28, 2020. Accepted for publication Apr 07, 2020.

doi: $10.21037 / \mathrm{atm} .2020 .04 .46$

View this article at: http://dx.doi.org/10.21037/atm.2020.04.46

A socioeconomic gradient in health is well-established in a large number of population-based cohort studies from several epidemiological settings (1-4), and is partially explained by the socioeconomic patterning of health behaviours across the population (5), differences in access to healthcare (6), differential exposure to environmental risk factors and to psychological stress (7).

However, the excess of mortality/disease risk associated with low socioeconomic position (SEP) is only partially mediated by known risk factors, and conclusions from different studies are often discordant on the actual magnitude of the effects of potential mediators.

This might be due to the intrinsic complexity of handling causality in social epidemiology, that is the study of how social factors are related to health and disease.

The study by Laine and colleagues, published in this issue (8) aimed at investigating the intermediate risk factors that may underlie the relationship between socioeconomic factors and mortality by analysing data from the LIFEPATH consortium, including seven cohort studies for a total of 179,090 individuals.

Potential mediators were a set of lifestyles (e.g., smoking, diet, physical activity), intermediate phenotype (body mass index), and co-morbidities (i.e., hypertension, diabetes and coronary artery disease).

In their analysis, the authors relied on a counterfactual approach, a causal thinking based on imagining the consequences of changing the value of a single factor in a comprehensive causal system (9).
The results showed that lower SEP (as measured by occupation) and education were associated with higher mortality risk, as expected, and in line with prior evidence from the same multi-cohort (10). The authors then investigated the counterfactual effects of both SEP and education, in order to show differences in effects under two hypothetical actions. In the first scenario, no action on socioeconomic conditions of lower SEP or lower education was taken, while the second one hypothesized an action aimed at improving socioeconomic conditions to higher SEP or higher education.

Finally, their study assessed the role of mediators under both actions and captured the natural direct effect (that is that obtained by raising education or SEP) and the natural indirect effect under joint mediation of a large panel of potential mediators (lifestyles, BMI and co-morbidities).

Results showed that through a scenario of higher education, that is if there were hypothetical interventions to raise education, total effects on mortality could be reduced by $15 \%$ for women and by $29 \%$ for men; in particular, $5 \%$ or $11 \%$ for women and men, respectively, via the indirect path of the mediators considered and $10 \%$ and $18 \%$, respectively, via all other pathways.

Interestingly, by raising SEP, the benefits were slightly more modest for men (20\% reduction in mortality, $17 \%$ through the direct pathway, and $3 \%$ by the indirect path of mediators) but were far smaller for women (the mortality gradient would decrease by $6 \%$ only).

Beyond the merit of relying on a methodological 
approach able to overcome some limitations of more traditional methods used so far to manage mediation, the results from the LIFEPATH corroborate and expand our knowledge on the relation between socioeconomic status (SES) and health and shed light on potential mechanisms that are on the pathway of this association.

Some key messages from this study deserve to be discussed especially from a public health perspective.

First, Laine et al. showed that differences in mortality were dependent on the socioeconomic indicator used, being higher for education compared with SEP; this aspect is of crucial importance since it supports the need of dealing with SEP and education as distinct but not interchangeably SES indicators.

Indeed, educational level is commonly used as a proxy for cultural resources, aims at capturing the knowledge-related assets of a person and is closely linked to the capacity of being more receptive to health education messages or more capable to access appropriate health services (11); on the other side, occupation is an indicator of both social standing and material reward and resources (12).

Second, the association between SEP and mortality varied by gender, being almost negligible for women; gender-related differences in health may depend either on the fact that position in a social or economic hierarchy is measured with less precision among women, or upon the choice of the summary of measure of inequality applied (13). As a consequence, these findings, along with prior works, seem to indicate that public health strategies should be gender-tailored to be actually effective.

Consistently, in the study by Laine et al. a hypothetical action to raise education from a lower to higher status was likely to be more effective than increasing SEP.

\section{The study from a public health perspective}

These findings are in agreement with recent evidence from a large Italian cohort study suggesting a predominant role of educational attainment over material resources (measured as an index including occupation, housing and overcrowding) in determining the risk of premature mortality or mortality from cardiovascular disease (CVD) (14). This might be interpreted in light of the fact that the sets of skills and knowledge likely associated with higher education are able to shape later adult health possibly by healthier choices as adopting high-quality diets or physical exercising; moreover, high educated subjects may have a better capacity to obtain, process and understand basic health information and services needed to make appropriate health decisions (15).

However, not all studies do agree: some found that income may be a predictor of mortality stronger than education, thus narrowing the income differentials may reduce the health disparities $(16,17)$.

The identification of main SES determinants of health and their pathways is of crucial importance and leads directly to the question on how SES disparities can be flattened.

To date, interventions targeting individual-level factors relied on actions aimed at improving health and lifestyle behaviors, flatten the gaps in accessibility of health care, reducing socio-contextual barriers, and delivering health programs that are culturally and linguistically tailored to specific individuals or groups (18).

As compared to the Nineties, when all efforts were largely focused on the understanding of the nature and extent of inequalities, more recently researchers are looking at the impact of interventions and policies to reduce health inequalities (19).

Pursuing equity in health is a major challenge to public health throughout Europe, also through funding large projects looking at the impact of interventions and policies to reduce health inequalities (19).

During the European Public Health Conference held in Glasgow in 2014, the whole public health community launched the ALL HANDS ON DECK! Philosophy, to make everyone aware that we need to go much further than 'mind the gap' in health inequalities (19).

\section{Tackling 'invisible' disparities in risk factors}

Targeting health-behaviors represents one of the possible areas of intervention to flatten SES disparities, although there is uncertainty on the actual effectiveness of interventions targeting health-related behavior among individuals with low SES (20).

Among lifestyles, a healthy diet in high-SES individuals is one of the mechanisms that explain social differences in health (21); it has been estimated that diet and lifestyle account for up to $70 \%$ of the educational differences in CVD risk, and that dietary behavior alone explained more than other lifestyle factors the educational differences in risk of developing CVD (22).

More recently, evidence from the Moli-sani Study, a large population-based cohort on 25,000 adult Italians (14), has highlighted the need of focusing on potential emerging disparities in diet (a major risk/protective factor for health) 
not only in terms of amount of food consumed, but also by looking at non-nutrient aspects, currently unaddressed in large epidemiological investigations, such as food processing, local production or organic farming. An analysis on 19,000 "Moli-sani" (23) indicated that cardiovascular risk reduction associated with a Mediterranean diet, known for its multiple health benefits (24), was limited to advantaged socioeconomic groups, while it was apparently ineffective among the weakest individuals; possibly, additional dietary differences among socioeconomic groups may partially account for disparities in health benefits observed over follow-up (23). Indeed, given a comparable adherence to the Mediterranean diet, the most advantaged groups were more likely to report a larger number of indices of diet quality as opposed to people with low SES. For example, within those having an optimal adherence to the Mediterranean diet, those people with high income (or higher educational level) consumed foods richer in antioxidants and polyphenols, had a greater diversity in fruit and vegetable intakes, and tended to consume more organic food as compared to conventionally grown foods (23).

These results should make us aware that we need to go much further than encouraging healthy diets among most deprived individuals. We should plan interventions that really fill the gap in access to healthy food, and this can just be done by recognizing that, at time of globalization, the amount of food consumed is not the only feature to be evaluated in view of long-term health endpoints.

To date, the available tools, both in terms of knowledge and public health interventions, appear to be insufficient to keep up with a rapidly evolving food system and risk to overlook that new, insidious disparities are actually threatening an already unjust and unfair society.

\section{Acknowledgments}

Funding: None.

\section{Footnote}

Provenance and Peer Review: This article was commissioned and reviewed by the Section Editor Dr. Jianrong Zhang, MD, MPH (PhD Candidate, Cancer in Primary Care Research Group, Centre for Cancer Research; Department of General Practice, Melbourne Medical School, Faculty of Medicine, Dentistry and Health Sciences, University of Melbourne; Victorian Comprehensive Cancer Centre, Melbourne, Australia).
Conflicts of Interest: All authors have completed the ICMJE uniform disclosure form (available at http://dx.doi. org/10.21037/atm.2020.04.46). The authors have no conflicts of interest to declare.

Ethical Statement: The authors are accountable for all aspects of the work in ensuring that questions related to the accuracy or integrity of any part of the work are appropriately investigated and resolved.

Open Access Statement: This is an Open Access article distributed in accordance with the Creative Commons Attribution-NonCommercial-NoDerivs 4.0 International License (CC BY-NC-ND 4.0), which permits the noncommercial replication and distribution of the article with the strict proviso that no changes or edits are made and the original work is properly cited (including links to both the formal publication through the relevant DOI and the license). See: https://creativecommons.org/licenses/by-nc-nd/4.0/.

\section{References}

1. Veronesi G, Ferrario MM, Kuulasmaa K, et al. Educational class inequalities in the incidence of coronary heart disease in Europe. Heart 2016;102:958-65.

2. Espelt A, Arriola L, Borrell C, et al. Socioeconomic position and type 2 diabetes mellitus in Europe 19992009: a panorama of inequalities. Curr Diabetes Rev 2011;7:148-58.

3. Bray BD, Paley L, Hoffman A, et al. Socioeconomic disparities in first stroke incidence, quality of care, and survival: a nationwide registry-based cohort study of 44 million adults in England. Lancet Public Health 2018;3:e185-93.

4. Bonaccio M, Di Castelnuovo A, Costanzo S, et al. Interaction between education and income on the risk of all-cause mortality: prospective results from the MOLISANI study. Int J Public Health 2016;61:765-76.

5. Bonaccio M, Di Castelnuovo A, Pounis G, et al. Relative contribution of health-related behaviours and chronic diseases to the socioeconomic patterning of low-grade inflammation. Int J Public Health 2017;62:551-62.

6. Moscelli G, Siciliani L, Gutacker N, et al. Socioeconomic inequality of access to healthcare: Does choice explain the gradient? J Health Econ 2018;57:290-314.

7. Marmot MG, Bosma H, Hemingway H, et al. Contribution of job control and other risk factors to social variations in coronary heart disease incidence. Lancet 1997;350:235-9. 
8. Laine JE, Baltar VT, Stringini S, et al. Reducing socio-economic inequalities in all-cause mortality: a counterfactual mediation approach. Int J Epidemiol 2020;49:497-510.

9. Höfler M. Causal inference based on counterfactuals. BMC Med Res Methodol 2005;5:28.

10. Stringhini S, Carmeli C, Jokela M, et al. Socioeconomic status and the $25 \times 25$ risk factors as determinants of premature mortality: a multicohort study and meta-analysis of 1.7 million men and women. Lancet 2017;389:1229-37.

11. Galobardes B, Shaw M, Lawlor DA, et al. Indicators of socioeconomic position (Part 1). J Epidemiol Community Health 2006;60:7-12.

12. Galobardes B, Shaw M, Lawlor DA et al. Indicators of socioeconomic position (part 2). J Epidemiol Community Health 2006;60:95-101.

13. Mustard CA, Etches J. Gender differences in socioeconomic inequality in mortality. J Epidemiol Community Health 2003;57:974-80.

14. Bonaccio M, Di Castelnuovo A, Costanzo S, et al. Socioeconomic trajectories across the life course and risk of total and cause-specific mortality: prospective findings from the Moli-sani Study. J Epidemiol Community Health 2019;73:516-28.

15. Baker DW, Wolf MS, Feinglass J, et al. Health literacy and mortality among elderly persons. Arch Intern Med 2007;167:1503-9.

16. Sabanayagam C, Shankar A. Income is a stronger predictor of mortality than education in a national sample of US adults. J Health Popul Nutr 2012;30:82-6.

Cite this article as: Bonaccio M, Di Castelnuovo A, de Gaetano G, Iacoviello L. Socioeconomic gradient in health: mind the gap in 'invisible' disparities. Ann Transl Med 2020;8(18):1200. doi: 10.21037/atm.2020.04.46
17. Geyer S, Peter R. Income, occupational position, qualification and health inequalities--competing risks? (comparing indicators of social status). J Epidemiol Community Health 2000;54:299-305.

18. Thornton RL, Glover CM, Cené CW, et al. Evaluating Strategies For Reducing Health Disparities By Addressing The Social Determinants Of Health. Health Aff (Millwood) 2016;35:1416-23.

19. Mackenbach JP. Health inequalities: learning how to "mind the gap". Eurohealth 2015;21:3-7.

20. Vilhelmsson A, Östergren PO. Reducing health inequalities with interventions targeting behavioral factors among individuals with low levels of education - A rapid review. PLoS One 2018;13:e0195774.

21. Darmon N, Drewnowski A. Does social class predict diet quality? Am J Clin Nutr 2008;87:1107-17.

22. Méjean C, Droomers M, van der Schouw Y', et al. The contribution of diet and lifestyle to socioeconomic inequalities in cardiovascular morbidity and mortality. Int J Cardiol 2013;168:5190-5.

23. Bonaccio M, Di Castelnuovo A, Pounis G, et al. High adherence to the Mediterranean diet is associated with cardiovascular protection in higher but not in lower socioeconomic groups: prospective findings from the Moli-sani study. Int J Epidemiol 2017;46:1478-87.

24. Dinu M, Pagliai G, Casini A, et al. Mediterranean diet and multiple health outcomes: an umbrella review of metaanalyses of observational studies and randomised trials. Eur J Clin Nutr 2018;72:30-43. 